\title{
Analysis of the meteorological situation during period of forest fires and smoke-blanketing monitoring in Siberia in 2019
}

\author{
O. A. Dubrovskaya ${ }^{1}$, A. A. Kostornaya ${ }^{2}$, I. A. Solovyeva ${ }^{2}$, I. A. Martynova ${ }^{2}$, \\ I. V. Rublev ${ }^{2}$, A. E. Voronova ${ }^{2}$ \\ ${ }^{1}$ Federal Research Center for Information and Computational Technologies, \\ Krasnoyarsk, 660049, Russia \\ ${ }^{2}$ Scientific Research Center "Planeta" Siberian Center, Moscow, 123242, Russia \\ E-mail: dubrovskaya_oa@list.ru
}

\begin{abstract}
We present an analysis of the synoptical conditions from July 15 to July 31, 2019, on the Siberian territory in the forest fire zone with the establishment of a blocking anticyclone over the smoke-blanketed area. We consider the dynamics of propagation the smoke plumes and various characteristics of the atmosphere over the area covered by in the smoke. Large and super-large fires were observed on the territory of the Krasnoyarsk Krai, Irkutsk Region, and the Republic of Sakha (Yakutia), united by a common zone of aerodynamic interaction of convective columns and atmospheric systems as satellite monitoring data shows. Disastrous forest fires significantly affect the development and movement of air masses.
\end{abstract}

Accepted: 15.09 .2020

DOI: 10.21046/2070-7401-2020-17-6-25-29

\section{Introduction}

July is the central summer month and the warmest month of the year. A vast area of low atmospheric pressure is usually observed over the Western and Central parts of Siberia in July. Compared to June, it deepens slightly due to the warming up of the mainland and vigorous cyclonic activity on the Arctic and Polar fronts.

Arctic air masses come to the mainland, quickly warm up, transform into continental air of midlatitudes and lead to aridness in Western Siberia. However, Atlantic western cyclones, which form on the Arctic and Polar fronts, increase the amount of moisture in the region in July. Local convection also contributes to the increase in water vapor, thus providing the maximum amount of precipitation in the annual cycle in almost the entire territory.

Most often, precipitation falls in the form of showers. On average, the amount of precipitation per month is $37-97 \mathrm{~mm}$, in some places in the Altai Republic and the mountains of the Kemerovo region, the total amount of precipitation reaches 99-147 mm. In the driest years $(1963,1965,1966,1974$, 1989, 1999, and 2012) in July, most of the territory received from 3 to $60 \%$ of the monthly rainfall, and in some regions, there was no precipitation at all. The average number of days with precipitation in July is 10-19, with a thunderstorm 7-13, with hail 1-4 days (in the South up to 6 days).

For the Western and Central parts of Siberia July is characterized by the lowest daily variability of air temperature. The average monthly air temperature is $1-5^{\circ} \mathrm{C}$ higher than in June. In some years, the average monthly air temperature can differ from the average long-term norm by $2-6^{\circ} \mathrm{C}$, both in the direction of warmth and in the direction of cold. The warmest July in the last thirty years was 
observed in 1989, 1990, 1998, 2007, and 2012. In some years, the maximum daytime air temperature rose to $+30,+37{ }^{\circ} \mathrm{C}$. The absolute maximum for Western Siberia in July is $+37,+41{ }^{\circ} \mathrm{C}$. Negative anomalies were noted less often - in 1997, 2001, 2010, 2011, and 2018.

In July in Western Siberia and in Krasnoyarsk Krai the winds from the northern quarter prevail. In the south of Krasnoyarsk Krai, along with the mountain ranges, westerly and south-westerly winds prevail. Foehn winds periodically blow on the northern slopes of the Eastern Sayan, associated with cyclonic activity in northern Mongolia. The average wind speed is $1-4 \mathrm{~m} / \mathrm{s}$, in case of thunderstorms, gust up to $28 \mathrm{~m} / \mathrm{s}$ are possible. In the steppe zone, the average number of days with a dust storm is 1-3 days, the average number of days with fog is from 1 to 12 .

\section{Overview of the synoptical conditions in the second half of July (15-31.07.2019)}

July 2019, over the southeast of Western Siberia, was characterized by moderately warm weather with a non-uniform distribution of precipitation over the territory.
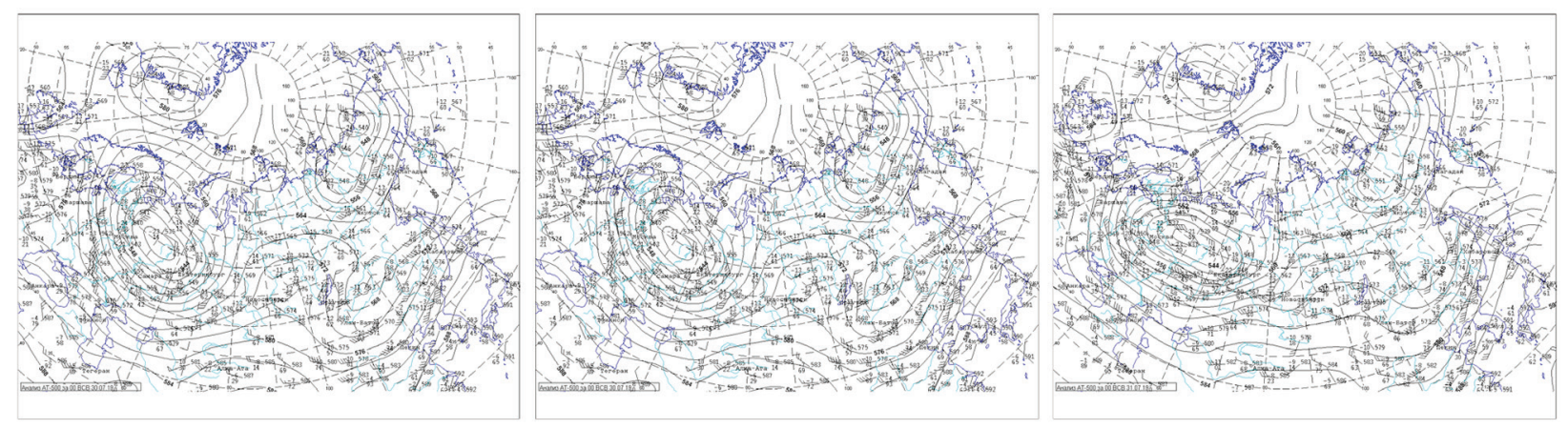

Figure 1. Geopotential height analysis maps at 500 hPa, July 29-31, 00:00 UTC.
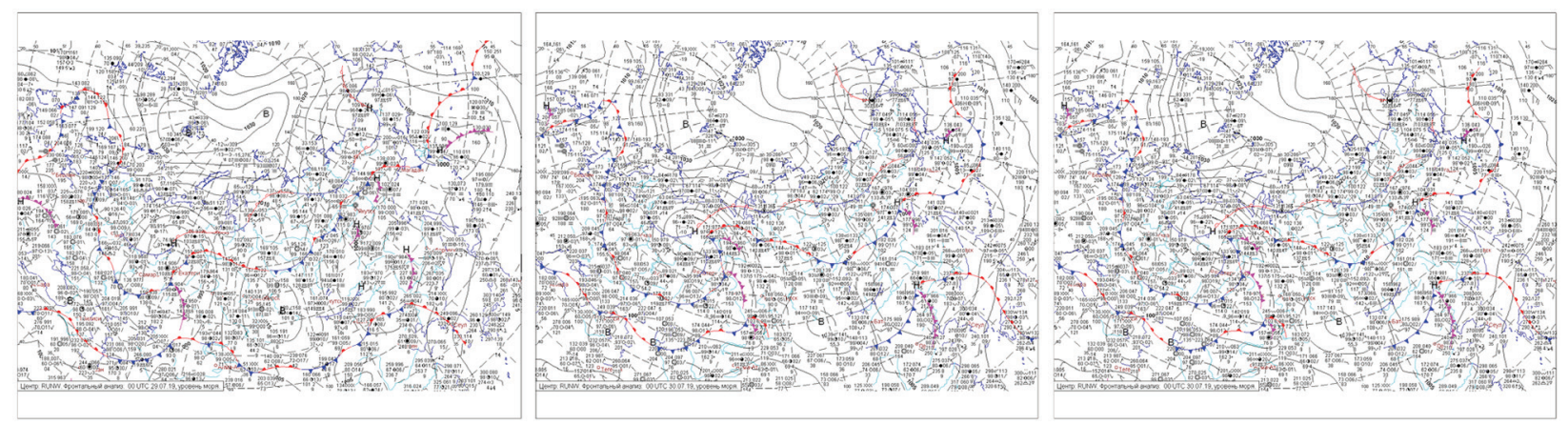

Figure 2. Surface analysis maps July 29-31, 00:00 UTC.

In the middle troposphere, meridional transfer of air masses prevailed with frequent passage of atmospheric fronts and intermediate ridges. In the second decade of the month, over the central and south-eastern regions of Western Siberia, the stationary and deep cyclonic vortex ranging throughout the entire height of the troposphere. Until the middle of the third decade, the upper-level cyclone retained its influence. In the middle troposphere, the north-eastern and northern transport of air masses prevailed. The cyclone reached its maximum depth on July 22-24, with the values on the geopotential height of the $500 \mathrm{hPa}$ surface at 556-552 hPa (geopotential decameters). At the same time, an area of increased pressure was located over the western, northern, and north-eastern regions of Western Siberia, as well as over the parts of Krasnoyarsk Krai, covering the Evenk Autonomous Okrug, and Turukhansk region. As a result, the cyclonic vortex was blocked over the south-eastern area of Siberia. In some periods the western periphery of the blocking anticyclone was deformed and partially destroyed. This contributed to an additional supply of warm and humid air to the cyclonice circulation and an increase in precipitation in the south-eastern regions. Nevertheless, the north-eastern part of Krasnoyarsk Krai was under the influence of the high-altitude anticyclone until the end of July, where a dry air mass was observed practically throughout July (Figure 1). 

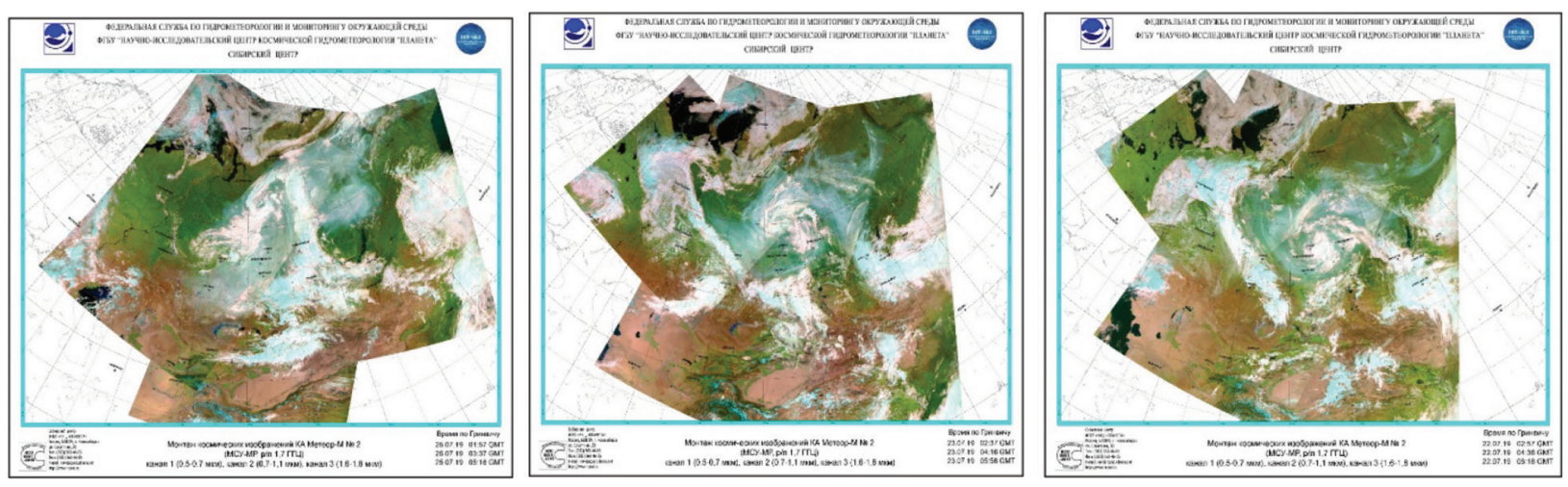

Figure 3. Distribution of the main atmospheric systems and cloud cover corresponding to them, 26, 28, 31 July 2019 (according to the Meteor-M No. 2 data).

Near the surface of the Earth in the south-eastern parts of the Siberia, as well as in the middle troposphere, the weather was determined by a multicenter, static depression, which promotes the development of active convection, thunderstorms and rains of varying intensity (Figure 2). In the western, northern, and north-eastern regions of Western Siberia, anticyclonic weather was noted on most days of July. Sunny, dry, and hot weather without precipitation prevailed (Figure 3). Research confirms the close connection between fire hazards and descending air movements over a large area (anticyclone) [1]. Thus, the highest fire hazards and forest fires developing to large sizes are noted, including in large anticyclones.

\section{Monitoring the propagation of smoke plumes}

According to SRC "Planeta" data, the fire hazard season of 2019 in Siberia started at the end of March due to the melting of seasonal snow cover and the steady warm and dry weather in the Republics of Buryatia, Khakassia, Zabaikalsky Krai, Krasnoyarsk Krai. The first fires were discovered in steppe and agricultural lands. In April 2019, in Zabaikalsky Krai, the transitions of steppe fires to the lands of the Forest Fund were repeatedly recorded. In the Kemerovo, Tomsk, Irkutsk and Omsk Oblast, the Republic of Altai, the Republic of Tyva and Altai Krai, the first fires were noted in April 2019.

During the first ten days of July, 5571 thermal hotspots were detected in Krasnoyarsk Krai. In the second decade of July, the number of fires increased to 9400 (Figure 4) caused by a deficit of precipitation. The total amount of fires detected per month was 30,432.

A difficult fire situation was also developing in Irkutsk Oblast. In the northern area, strong wind contributed to the spread of fire to a large scale, and the remoteness and inaccessibility of the fires only exacerbated the situation.

From the beginning of July to the end of August, a difficult fire situation was observed in some areas of the Republic of Sakha (Yakutia), bordering Irkutsk Oblast and Krasnoyarsk Krai.

The fire hazard season of 2019 was distinguished not only by catastrophic long-term fires in Siberia but also by significant smoke-blanketing as a result of the intense burning of a large amount of biomass. Because of the synoptical conditions in the second half of July, there was an intensive transfer of smoke from Eastern Siberia in the western direction to the territory of Western Siberia, the Urals, the European part of Russia, and even Kazakhstan.

In the period from 20th to 25th of July, a stable north-eastern transport was established in the middle troposphere, contributing to the inflow of air masses from the north-eastern regions of Krasnoyarsk Krai, were all aflame (Figure 4). The cyclonic vortex involved not only cloud masses in its circulation, but also the smoke from forest fires.

To assess the situation, we used the satellite data that made it possible to trace the distribution and the dynamics of smoke plumes. The parameters calculated from satellite data (such as aerosol index (Figure 5), optical depth, cloud types, cloud phase, cloud drop effective radius, maximum possible precipitation intensity (Figure 6)) allow one to assess the degree of air pollution and the effect of greenhouse gas emissions on the cloudiness and weather conditions. 

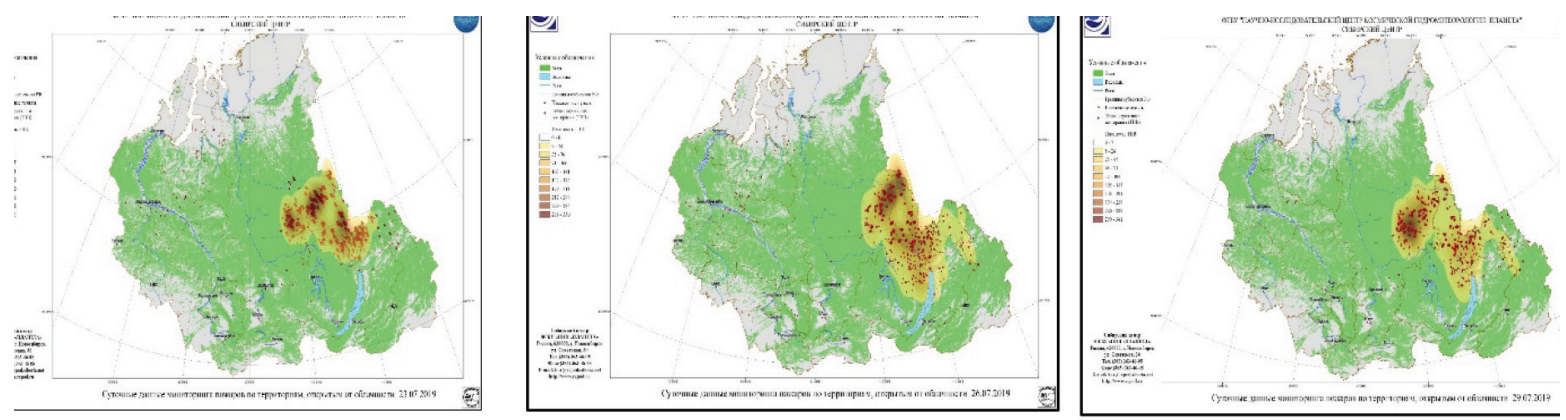

Figure 4. Hot spots maps from satellite data for 22, 26, 28 July 2019.

The satellite images clearly show a vast area of smoke propagation, exceeding the area of fires by several hundred times. Aerosol index values of more than 2 or 3 indicate very high concentrations of aerosol particles [2]. On the aerosol index maps from SUOMI NPP/OMPS spacecraft (Figure 5), the values at some points are $>4$. Smoke plumes spread far to the west and southwest, reaching the Urals and northern Kazakhstan. This led to air quality deterioration in Siberia and beyond, and the formation of such an atmospheric phenomenon as haze.


Figure 5. Distribution of smoke plumes from forest fires on July 26, 28, 31, 2019 (aerosol index maps from SUOMI NPP/OMPS data).
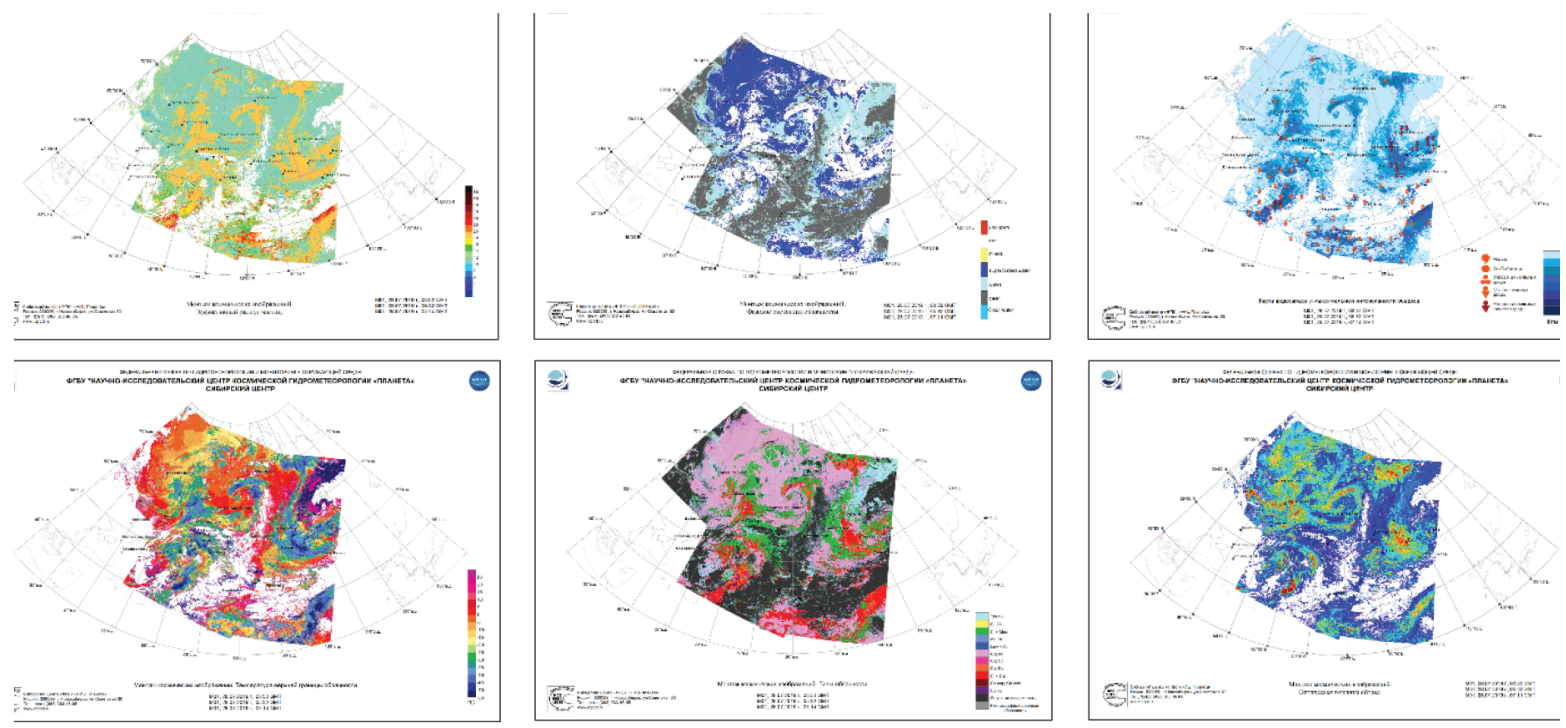

Figure 6. Cloud parameters maps: cloud drop effective radius, cloud phase, optical depth, cloud water content, maximum possible precipitation intensity, cloud height, and cloud top temperature, cloud types.

Aerosol significantly affects the development and movement of air masses [3-5]. In articles [6, 7] it is noted that high concentrations of aerosol particles lead to a decrease in the concentration of drops and destruction of clouds. However, the processes of interaction of aerosol with a cloud are very much complicated. An increase in an atmospheric aerosol can lead to the development and destruction of clouds, depending on the specific environmental conditions [8-11]. In our case, the prevailing weath- 
er conditions (anticyclone) and the effect of aerosol on the growth of cloud droplets led to the suppression of precipitation.

By the end of July, the blocking ridge in the middle troposphere collapsed. As a result, the direction of the movement of air masses changed from northeast to northwest. This contributed to the movement of atmospheric fronts and the development of cloudiness, precipitation over areas with forest fires, and a general improvement of air quality.

\section{Conclusion}

The forest fires that occurred in Western Siberia in July 2019 became one of the largest in the past 20 years. Smoke plumes have spread over vast territories and led to air quality deterioration in many large cities, causing a massive public outcry.

For the study of the processes associated with the spread and influence of forest fires, remote sensing data is of considerable interest. Modern methods and technologies for satellite data processing make it possible to trace the propagation of smoke plumes. Using the atmospheric and clouds parameters derived from remote sensing data we can analyse the level of air pollution and assess the impact of greenhouse gas emissions on cloudiness and weather conditions.

Satellite remote sensing continues to be the main source of global data on the interaction of aerosol and clouds [12]. At present, the fundamental problem remains to study the effect of aerosols from mass forest fires on the processes of cloud and precipitation formation, on atmospheric dynamics, and changes in cloud properties. These factors affect the weather of the whole region and may have an impact on the Climate Change.

\section{References}

[1] Kozlov V. N., Electrical methods artificial control of precipitation, Diss. Dr. Sci., Saint Petersburg, 2013, 24 p.

[2] Tomshin O.A., Protopopov A. V., Solovyev V. S., Study of atmospheric aerosol and carbon monoxide variations over forest fires, Sovremennye problemy distantsionnogo zondirovaniya Zemli iz kosmosa, 2012, V. 9(1), pp. $145-150$.

[3] Clarke A. D., Kapustin V.N., Eisele F.L., Weber R.J., McMurry P.H., Particle production near marine clouds: Sulfuric acid and predictions from classical binary nucleation, Geophysical Research Letters, 1999, Vol. 26, pp. 2425-2428.

[4] Petters M.D., Snider J.R., Stevens B., Vali G., Faloona I., Russell L. M., Accumulation mode aerosol, pockets of open cells, and particle nucleation in the remote subtropical Pacific marine boundary layer, $J$. Geophysical Research, 2006, Vol. 111(D2), D02206, 15 p.

[5] Anderson T. L., Ackerman R.A., Harmann D. L., Isaac G. A., Temporal and spatial variability of clouds and related aerosol, Clouds in the Perturbed Climate System: Their Relationship to Energy Balance, Atmospheric Dynamics, and Precipitation, R. J. Charlson, J. Heintzenberg (eds.), Cambridge, MA, USA: MIT Press, 2009, pp. 127-148.

[6] Verheggen B., Cozic J., Weingartner E., Bower K., Mertes S., Connolly P., Gallagher M., Flynn M., Choularton T., Baltensperger U., Aerosol partitioning between the interstitial and the condensed phase in mixed-phase clouds, J. Geophysical Research, 2007, Vol. 112(3) D23202, 13 p.

[7] Koren I., Martins J.V., Remer L. A., Afargan H., Smoke invigoration versus inhibition of clouds over the Amazon, Science, 2008, Vol. 321, pp. 946-949.

[8] Engström A., Ekman A. M.L., Impact of meteorological factors on the correlation between aerosol optical depth and cloud fraction, Geophysical Research Letters, 2010, Vol. 37(18), L18814, 4 p.

[9] Boucher O., Quaas J., Water vapour affects both rain and aerosol optical depth, Nature Geoscience, 2013, Vol. 6, pp. 4-5.

[10] Sato Y., Suzuki K., How do aerosols affects cloudness?, Science, 2019, Vol. 363(6427), pp. 580-581.

[1] Rosenfeld D., Zhu Y., Wang M., Zheng Y., Goren T., Yu S., Aerosol-driven droplet concentratilons dominate coverage and water of oceanic low-level clouds, Science, 2019, Vol. 363(6427), eaav0566.

[12] Boucher O., Randall D., Artaxo P., Bretherton C., Feingold G., Forster P., Kerminen V.-M., Kondo Y., Liao H., Lohmann U., Rasch P., Satheesh S. K., Sherwood S., Stevens B., Zhang X.Y., Clouds and Aerosols, Climate Change 2013: The Physical Science Basis. Contribution of Working Group I to the Fifth Assessment Report of the Intergovernmental Panel on Climate Change, T. F. Stocker, D. Qin, G.-K. Plattner, M. Tignor, S. K. Allen, J. Boschung, A. Nauels, Y. Xia, V. Bex, P. M. Midgley (eds.), Cambridge, United Kingdom; New York: Cambridge University Press, 2013, pp. 571-657, available at: https://www.ipcc.ch/ site/assets/uploads/2018/02/WG1AR5_Chapter07_FINAL-1.pdf. 